\title{
CONCEPTUALIZE-DESIGN ENHANCEMENT OF SYSTEMATIC DESIGN ENGINEERING METHOD
}

\author{
W. Ernst Eder \\ Royal Military College of Canada (retired) \\ eder-e@kos.net
}

\begin{abstract}
The engineering design methodology of Pahl and Beitz is good in the detailed stages, but needs enhancement in the early stages of conceptualizing and embodiment-in-principle. The concept of 'functions' has been enhanced by Hubka and colleagues.

A 'functional basis' (Hirtz et al) has improved the definitions of 'flows' and 'functions', their work does not go far enough to provide a basis for conceptualizing. 'Affordances' (Maier and Fadel) are covered by full use of systematic conceptualizing of design engineering solutions.

The Pahl-Beitz model and method of 'decomposition of functions', 'physics', and components is contrasted with the Hubka models of a transformation system, TrfS, its constituents, structures, properties life cycle, etc., and their use as method for design engineering by searching for alternative embodiments at each of these levels of abstraction.

These steps are illustrated in (to date) 21 case examples published between 1976 and 2012, several of them in the CEEA conferences and their predecessors.
\end{abstract}

Keywords: Systematic engineering design, conceptuallizing, application of methods

\section{INTRODUCTION}

In most of the English-speaking world, academic staff of engineering departments have little if any experience of working in industry. Especially the knowledge and experience of engineering design is largely absent. Where appointed individuals (e.g. Professors of Engineering Design brought from industry) have such knowledge, these staff members seem to assume that their own experience is sufficient to be able to impart design knowledge and experience to their students. Professors to lecturers usually do not have an explanatory framework available to guide them into a fuller understanding of that essential element that constitutes the major difference between engineering and the sciences - design engineering.
The main emphasis in University teaching of engineering (in all disciplines) is in using the mathematical tools of the engineering sciences for analysis. Equally important aspects for design engineering are (a) the use of mathematical tools for synthesis, especially 'order-of-magnitude' estimations, and 'what if?' investigations [1],[2], and (b) some conceptual, visual and practical insight into and understanding of the behaviour of real engineering devices and components.

The discussions in this paper are based on the author's experience, 'on the drawing board' in industry, and helping in the developments of design thinking pioneered by Vladimir Hubka [3],[4],[5],[6].

\section{A PRAGMATIC ENGINEERING DESIGN METHODOLOGY}

The methodology developed by Pahl and Beitz [7] (and largely adopted by VDI - Verein deutscher Ingenieure, Association of German Engineers) was derived directly (as a design methodology) and pragmatically from the engineering design experience of the authors. This engineering design methodology is good in the later embodiment detailed stages, with ample advice for many aspects of layout and detail. The descriptive (non-mathematical) theory underpinning this Pahl-Beitz design methodology tends to be somewhat rudimentary, with little attempt at completeness and comprehensive applicability for all engineering products - technical systems. The methodology needs enhancement in the early stages of conceptualizing and embodiment-in-principle, especially where a novel product or a radical innovation is desired.

The highest abstraction recognized by Pahl-Beitz is the 'function structure', a structure consisting of interrelated functions. A 'function' is defined as the capability for doing something (simple to complex), and is formulated in a verb or verb phrase combined with a noun or noun phrase. A main purpose function needs to be recognized, which is subjected to 'function decomposition' to recognize the sub-functions and 
(eventually) elemental functions which cannot (usefully) be further decomposed, see figure 1. Few methodical tools and guidelines are offered to help with this decomposition.

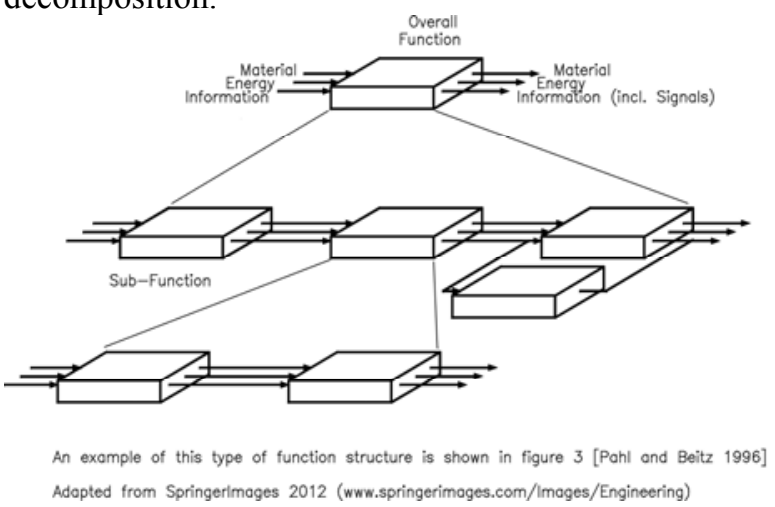

Fig. 1. Function Decomposition according to Pahl and Beitz [7]

The overall design process is illustrated as in figure 2 . It is noteworthy that sub-processes such as 'evaluating' and 'deciding' are only implied, and that 'searching for solutions' is specifically mentioned as step 3, but only in the context of 'principle solutions'

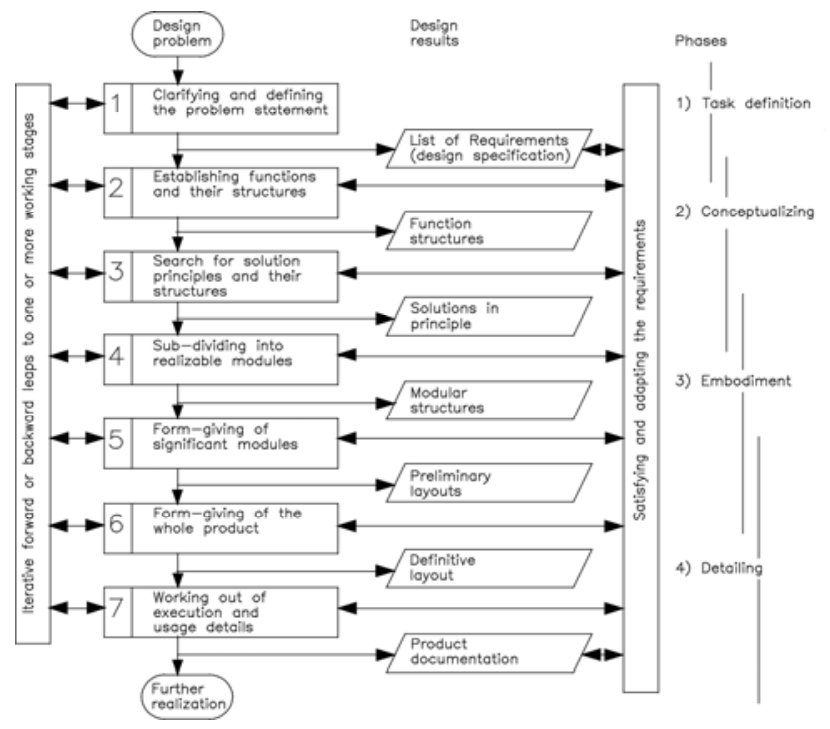

Fig. 2. Design Methodology according to VDI 2221 [8],[9]

The transition from the function structure towards the components is achieved by applying 'physics' (covering all modes of action). Koller [10],[11] and Ehrlenspiel [12],[13] have provided extensive tables for all physical quantities, including possibilities of chaining of physical quantities and phenomena, and the basic analytical equations.

\section{THEORY-BASED ENGINEERING DESIGN METHODOLOGY}

As formulated in cybernetics [14], 'both theory and method emerge from the phenomenon of the subject'. A close relationship should exist between a subject (its nature as a concept or object), a basic theory (formal or informal, recorded or in a human mind), and a recommended method - the triad 'subject - theory method'. The theory should describe and provide a foundation for explaining and predicting 'the behavior of the concept or (natural or artificial, process or tangible) object', as subject. The theory should be as complete and logically consistent as possible, and refer to actual and existing phenomena. A useful method (a) for using the subject, and (b) for designing the subject, can then be derived, and recommended as a choice considering the available experience.

Hubka [3],[4],[5],[6] strictly separates theory from method. The theory is a basis for an explanatory framework to show the needs, procedures and contexts of design engineering. Method is voluntary, can be used selectively as needed, and is supported by experience, opportunistic, intuitive and idiosyncratic behaviour, creativity, etc. Other pragmatic, 'industry best practice', theory-based, and computer-assisted methods can be interspersed as a need arises.

\subsection{Existing Transformation Systems}

Figure 3 shows the basic model on which the theory (and the method, see section 3.2 below) is based. This model of the transformation system declares [5],[6]:

- An operand (materials, energy, information, and/or living things $-M, E, I, L)$ in state Od1 is transformed into state Od2, using the active and reactive effects (in the form of materials, energy and/or information - M, E, I) exerted continuously, intermittently or instantaneously by the operators (human systems, technical systems, active and reactive environment, information systems, and management systems, as outputs from their internal processes), by applying a suitable technology $\mathrm{Tg}$ (which mediates the exchange of $M$, E, I between effects and operand), whereby assisting inputs are needed, and secondary inputs and outputs can occur for the operand and for the operators. 


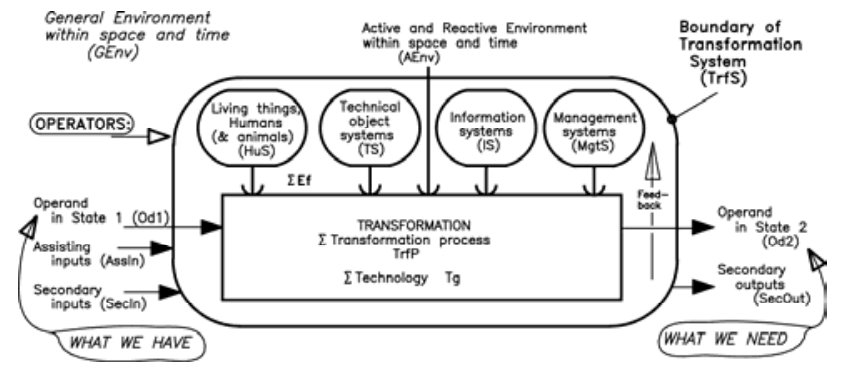

Fig. 3. General Model of a Transformation System [5],[6]

Hubka's additional models cover:

(a) the transformation process, TrfP, recognizing a structure of operations in the TrfP, and the operand in its initial state, Od1, and its final state, Od2;

(b) the means and technologies, $\mathrm{Tg}$, by which these TrfP operations are performed;

(c) the effects needed to drive the technologies, as output from one or more of the typically five operators;

(d) the TS-internal and cross-boundary functions, $\mathrm{Fu}$, needed to produce the effects developed in (c), including aesthetic and ergonomic functions ('functions' according to Hirtz et al);

(e) the organs and constructional parts that exist to realize the manufactured TS (this is where Pahl and Beitz including the engineering science 'physics');

(f) TS-life cycle, states of existence and operation of TS, properties of TS, general development in time, and other influences;

The function structure, organ structure and constructional structure co-exist in any one TS, but usually not in a 1:1 correspondence, see figure 4.

Seven (typical) stages of life cycle processes can be defined: LC1 - product planning, LC2 - product designing, LC3 - manufacturing planning, LC4 manufacturing, LC5 - product distributing, LC6 - product in use (LC6A - product being serviced, maintained, repaired, etc.), LC7 - product liquidation. Real TS(s) life cycles consist of many more such transformation systems, these seven stages are a necessary minimum, and a maximum that preserves complete generality for all TS. The subscript '(s)' is added to designate that TS as the subject of interest - many other TS influence the lifecycle of the TS(s).

All products carry their properties, whether they have been deliberately designed, or occur as by-product of existence [15]. Many of these properties are necessary, they provide the purpose of the technical system, TS(s), its physical presence, and the outputs (effects, Ef) that can drive the transformation processes we wish to perform, TrfP.

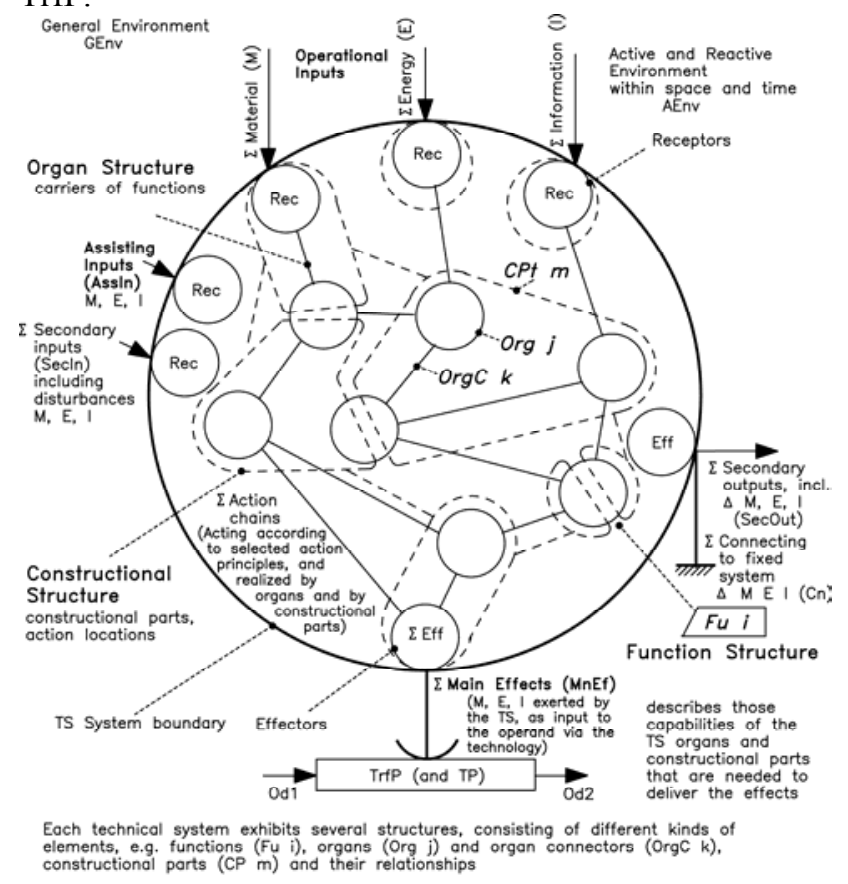

Fig.4. TS-internal and Cross-boundary Structures [5],[6]

A complete theory-based classification for the properties of existing 'as is' transformation processes, TrfP, and 'as is' technical systems, TS(s), can be derived from figure 3 , by considering life cycle stages LC4 - LC7 (and the operators of each of these life-cycle stages), and adding three axiomatic classes: intrinsic (experiencebased and heuristic), general (engineering sciences-based - these two are the mediating properties), and elemental design properties (those directly established by the engineering designer) [5],[6]. This classification is complete, no other classes are needed. The general design properties include the Pahl-Beitz/Koller/Ehrlenspiel 'physics'.

\subsection{Designing of Future Transformation Systems}

Using the model of the transformation system (figure 3) as basis, the stages and steps of a systematic engineering design process for a novel product, TS(s), can be derived [5],[6], and used for design engineering by searching for alternative embodiments at each level of abstraction. The most important steps, using the numbering of the full listing [6, figure 11.1], are summarized as:

- task defining:

(P1) establish a design specification for the required system, a list of requirements; 
(P2) establish a plan and timeline for the process of design engineering;

\section{- conceptualizing:}

(P3a) from the desirable and required output (operand in state $\mathrm{Od} 2$ ), establish a suitable transformation process $\operatorname{TrfP}(\mathrm{s})$

(P3.1.1) if needed, establish the appropriate input (operand in state Od1);

(P3.1.2) decide which of the operations in the $\operatorname{TrfP}(\mathrm{s})$ will be performed by technical systems, TS, alone or in mutual cooperation with other operators; and which $\mathrm{TS}(\mathrm{s})$ (or parts of them) need to be designed;

(P3.1.3) establish a technology (structure, with alternatives) for that transformation operation, and therefore the effects (as outputs) needed from the technical system;

(P3b) establish what the technical system needs to be able to do (its internal and cross-boundary functions, with alternatives);

(P4) establish what organs (function-carriers in principle and their structure, with alternatives) can perform these functions. These organs can be found mainly in prior art, especially the machine elements, in a revised arrangement as proposed by Weber [16],[17],[18];

\section{- embodying/laying out and detailing:}

(P5a) establish what constructional parts and their arrangement are needed, in sketch-outline, in rough layout, with alternatives;

(P5b) establish what constructional parts are needed, in dimensional-definitive layout, with alternatives;

(P6) establish what constructional parts are needed, in detail and assembly drawings, with alternatives.

The suffix '(s)' indicates that this $\operatorname{TrfP}(\mathrm{s})$ and/or TS(s) is the subject of interest. Only those parts of this engineering design process that are thought to be useful are employed. Such an 'idealized' procedure cannot be accomplished in a linear fashion - iterative and recursive working is essential, using analysis and synthesis [19],[20].

Adaptation for redesign problems (probably about 95\% of all design engineering tasks) proceeds through stages (P1) and (P2) above, then analyzes from (P6) or $(\mathrm{P} 5 \mathrm{~b})$ to $(\mathrm{P} 4)$, and/or to $(\mathrm{P} 3 \mathrm{~b})$ to 'reverse-engineer' these structures, modify them according to the new requirements, and use the stages in the usual order to complete the redesign.

For designing of novel products and radical innovations, it is important to recognize the operand of the transformation process under consideration. Even for re-design problems, the author has found it useful to recognize the operand, though it plays no specific role in the re-design process.

The list of requirements (step P1) can be based on the complete list of classes [6, figure 11.4], consisting of requirements for the manufacturing organization (life cycle stages LC1-LC3), requirements for the transformation process, TrfP (in analogy to the TrfPproperties), and requirements for the technical system, TS(s) (in analogy to the TS-properties).

Superimposed on the (systematic) engineering design process as outlined above is a frequently-applied problem-solving sequence, the cycle of basic operations, which applies to each of the design process steps. This problem-solving proceeds in four operational steps:

Op-H3.1 determining, defining and clarifying the task ('framing' the problem),

Op-H3.2 searching creatively and routinely for likely (and alternative candidate) solutions, principles and means at differing levels of abstraction,

Op-H3.3 evaluating, optimizing, improving, making decisions, and selecting the preferred or most promising solution(s), and

Op-H3.4 fixing, describing, capturing the 'design intent', communicating the solution, transmitting to the records, the next phase, stage, step, or organization function.

These operations use three supporting operations:

$\mathrm{Op}-\mathrm{H} 3.5$ providing and preparing information,

Op-H3.6 checking, including auditing, verifying, validating and reflecting, and

Op-H3.7 representing, with data, solution proposals, etc. It is noteworthy that 'searching for solutions' and 'evaluating' are thus applicable to any of the steps and phases of the engineering design process. The supporting operations appear only in this model of problem-solving, no other model of problem-solving makes specific mention of them.

In many cases of more complex design engineering of technical systems, only a selection of the TS-internal and cross-boundary functions proposed in (f) need to be initially considered to establish the main TS(s). Those functions that are (at that stage) initially relatively unimportant can then be elevated to transformation processes (TrfP) for the next more detailed stage of designing - a sub-problem, which can be solved using the same systematic method if needed. Equally, the transformation process (TrfP) for a more complex TS(s) can reappear as a TS-internal or cross-boundary function in a higher-order transformation system. Systems are hierarchical.

The models of Hubka encompass all possible modes of action of technical products. Each mode of action (way of operating) is based on an action principle, usually supported by an engineering science - mechanical, hydraulic, pneumatic, electrical, electronic/analog, electronic/digital, building, civil-structural, chemical, optical, nuclear, biomedical, software, or other discipline or engineering branch, singly or in a hybrid combination, in a static and/or dynamic mode - 'high-tech' products are mostly hybrids of mechanical, computer, and other 
disciplines. Mechatronics and nanotechnology are the result of automation and miniaturization.

The concept of 'functions' has thus been enhanced, and more clearly defined, by Hubka and colleagues. The Pahl-Beitz 'decomposition of functions' is contrasted with Hubka's proposal to separate the transformation process, TrfP, and the TS-internal and cross-boundary functions, and to use them sequentially in designing.

\section{SOME ENHANCEMENT PROPOSALS}

Closely following the 'function' definitions provided by Pahl et al [7], Hirtz et al [21] have attempted a reconciliation of several proposals for a complete list of 'functions'. As distinct from previous proposals, in their 'functional basis' they separate 'flows' from 'functions'. In terms of Hubka's theories, the Hirtz et al 'flows' are either transformation operations, or operator effects exerted via technologies on the operand. The Hirtz et al 'functions' are equivalent to the TS-internal and crossboundary functions. The listings provided are mainly the appropriate verbs (what is being done?) - verb phrases are hardly considered, nouns and noun phrases (to what is it being done?) Are omitted because they are likely to be product-specific

Maier and Fadel [22] proposed 'affordances' as requirements and TS-properties that allow a user to do something with a technical system - they are all included in the requirements for TrfP and TS, mainly as observable properties, especially where the TS is an operand or a reactive operator in the considered transformation system (TrfS). For this purpose, the TrfP should be as complete as necessary. For instance, a step-ladder, an example used by Maier and Fadel [22], is almost purely reactive to its loading - its transformation process operations could be established as shown in figure 5.

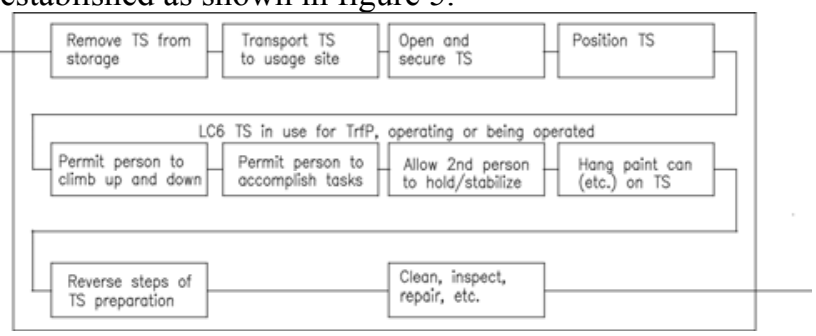

Fig. 5. Transformation Process for Ladder

Maier's 'DAU' (design team, artifact, user) [23] model shows that these factors, plus other factors of the active and reactive environment, can influence each other, but does not specify in what way the influences can be exerted or used for designing. A research study shows a time sequence for DAU-internal interactions [23] during a student design project for industry.

\section{VERIFICATION}

These steps of the Hubka systematic engineering design methodology are illustrated in (to date) 21 case examples published between 1976 and 2012, several of them in the CEEA conferences and their predecessors. Hubka's engineering design methodology is demonstrated by the scope and variety of our case examples. Care should be exercised when reading these case examples, they were not intended to show a plausible optimal resulting proposed technical system, TS(s) - the '(s)' indicates that this TS is the subject of interest - and some of these cases are doubtful in that respect. The initials in brackets after the case title indicate the originator - $(\mathrm{VH})$ $=$ Vladimir Hubka, $($ MMA $)=$ Mogens Myrup Andreasen, $(\mathrm{WEE})=\mathrm{W}$. Ernst Eder, and $(\mathrm{SH})=$ Stanislav Hosnedl.

The first case study, systematic according to the state of the theory and method at that time, appeared in [24] - a machine vice (VH). Hubka and Eder [25] included the second case study - a welding positioner (VH). The next three case examples, also systematic, were published in 1981 in German - a riveting fixture (VH), a milling jig $(\mathrm{VH})$, and a powder-coating machine (MMA) - the first two were systematic, the third took a more industrialartistic design approach [26]. Another set was published in 1983 in German - a P-V-T-experiment (WEE), a hand winding machine for tapes $(\mathrm{VH})$, and a tea brewing machine (MMA) - again, the third took an industrialartistic design approach. An English edition of case studies was finally published in [27], after revisions requested by the publisher, and included the existing six case studies first published in German language, plus two new items - a wave-powered bilge pump for small boats (MMA), and an oil drain valve ( $\mathrm{VH}$ - and again the bilge pump only loosely followed the systematic method.

Three further case studies were published in [5] - the tea machine revised to current systematic procedures showing enhanced engineering information (WEE); redesign of a water valve (WEE - first demonstration of systematic re-design); and an electro-static smoke gas dust precipitator, with rapper for dust removal (WEE first demonstration of treatment for sub-problems) [28]. The most recent book in this sequence [6] contains three new case studies, a portable frame for static trapeze display demonstrations (WEE) [29] which was built and used, re-design of an automotive oil pump (WEE second demonstration of re-design) [30], and a hospital intensive care bed ( $\mathrm{SH}$ - second demonstration of treatment for sub-problems) - the latter shows cooperation between industrial design and design engineering [31], and is one of many projects operated in cooperation with Czech industry. Hosnedl has also introduced the Hubka theories and methods into industrial use. Two new cases were presented at the International Conference DESIGN 2012 (WEE) [32],[33], both sub- 
systems from the Caravan Stage Barge [34] which has been in operation in Canadian and U.S.A. coastal waters, and now in the Mediterranean, since 1995. The Canadian Engineering Education Association $3^{\text {rd }}$ Annual Conference 2012 received two further case examples (WEE), a sub-system of the Caravan Stage Barge [35], and a sub-system for a wind tunnel balance [36].

The primary purpose of these case studies is to present examples for procedural application of the recommended engineering design method that students and practitioners can follow and study to help learn the scope of the method and its models. This purpose has been applied in courses at the Eidgenössische Technische Hochschule (ETH) by Dr. Vladimir Hubka (1976-2000), at The Royal Military College of Canada (1981-2006) by the author, and at the University of West Bohemia (1990-present) by Prof. Stanislav Hosnedl - for all levels of education and for industry consultations. A secondary purpose was to verify and validate the theory and its models, and the method derived from the theory. The emphasis in all case studies was on the engineering design procedure and use of the models.

Of course, the individual models and methods of the full engineering design methodology are available for selective application, as the designer (or team) consider it useful. More experienced engineering designers, and those working on more routine problems, will tend to work more intuitively, and at low mental energy [37]. When an unfamiliar situation arises, and competence is lacking, the models and methods of the full systematic engineering design methodology can be useful to 'break the log-jam'. Management is encouraged to insist on all results of designing being brought into the full methodology - a well-documented design process can then be available in case of litigation.

\section{CLOSURE}

The Hubka theory and method should be the preferred teaching tool for engineering design throughout the curriculum, It is currently the most comprehensive and well-founded system of knowledge for design engineering.

\section{References}

[1] Eder, W.E., 'Analysis, Synthesis and Problem Solving in Design Engineering', paper 2-13, session W3 SIG-AEDS, in Proc. International Conference on Engineering Design, ICED 09, August 24 - 27, 2009, Stanford University, Stanford, California, USA

[2] Eder, W.E., 'Theory of Technical Systems - Relationships to Engineering Sciences', paper 3 in Proc. CEEA 2011
Conference, 6-8 June 2011, Memorial University, St. Johns, Newfoundland

[3] Hubka, V., and Eder, W.E. (1988) Theory of Technical Systems: A Total Concept Theory for Engineering Design, New York: Springer_Verlag

[4] Hubka, V. and Eder, W.E. (1996) Design Science: Introduction to the Needs, Scope and Organization of Engineering Design Knowledge, London: Springer-Verlag, http://deseng.ryerson.ca/DesignScience/

[5] Eder, W.E. and Hosnedl, S (2008) Design Engineering: A Manual for Enhanced Creativity, Boca Raton: CRC-Press

[6] Eder, W.E. and Hosnedl, S. (2010) Introduction to Design Engineering - Systematic Creativity and Management, Leiden (The Netherlands): CRC Press / Balkema

[7] Pahl, G., Beitz, W., Feldhusen, J. and Grote, H-K., Engineering Design (3 edn.), London: Springer-Verlag, 2007 (1 edn. 1984) (Edited and translated by K. Wallace and L. Blessing), translated from 2003-5th edn. of Pahl, G. and Beitz, W., Feldhusen, J. and Grote, H-K. Konstruktionslehre, Methoden und Anwendungen, (7 edn.) Berlin/Heidelberg: Springer-Verlag, 2007 (1 edn. 1977)

[8] - VDI Richtlinie 2221:1985 Methodik zum Entwickeln und Konstruieren technischer Systeme und Produkte (Methodology for Developing and Designing Technical Systems and Products), Düsseldorf: VDI, 1985

[9] - VDI Guideline 2221: Systematic Approach to the Design of Technical Systems and Products, Düsseldorf: VDI (edited by K.M. Wallace), 1987

[10] Koller, R., Konstruktionsmethode für Maschinen-, Geräte- und Apparatebau (Design Method for Machine, Device and Apparatus Construction), Berlin/Heidelberg: Springer-Verlag, 1979

[11] Koller, R., Konstruktionslehre für den Maschinenbau (Study of Designing for Mechanical Engineering, 2. edn.), Berlin/Heidelberg: Springer-Verlag, 1985

[12] Ehrlenspiel, K., Integrierte Produktentwicklung Methoden für Prozeßorganisation, Produkterstellung und Konstruktion (Integrated Product Development - Methods for Process Organization, Product Realization and Design), München: Carl Hanser Verlag, 1995

[13] Ehrlenspiel, K., Kiewert, A. and Lindemann U, Kostengünstiges Entwickeln und Konstruieren (Cost Favorable Developing and Designing), ( $5^{\text {th }}$ edn.) Berlin: Springer-Verlag 2005 ( $1^{\text {st }}$ edn. 1985); and Cost Efficient Design, Berlin: Springer-Verlag and New York: ASME, 2007

[14] Klaus, G., Kybernetik in philosophischer Sicht (Cybernetics in Philosophical View) 4th edn., Berlin: Dietz Verlag, 1965 
[15] Eder, W.E., 'Properties of Technical Systems - Key to Crossing Design Boundaries', in Proc. Canadian Design Engineering Network Conference CDEN, 24-26 July 2006, Toronto, ON, 2006, on CD-ROM

[16] Weber, C. and Vajna, S. (1997) 'A New Approach to Design Elements (Machine Elements)'. In Riitahuhta, A. (ed.) WDK 25 - Proc. ICED 97 Tampere, Tampere University, Vol. 3, 1997, p. 685-690

[17] Eder, W.E. (2004) 'Machine Elements - Integration Of Some Proposals', Proc. AEDS 2004 Workshop, The Design Society - AEDS-SIG, 11-12 Nov 2004, Pilsen, Czech Republic, on CD-ROM, http://www.kks.zcu.cz/aeds

[18] Eder, W.E. (2005) 'Machine Elements - Revision and Outlook for Design Education', in Proc. Second CDEN International Conference, University of Calgary, Alberta, 18-19 July 2005 at Kananaskis Resort, paper 10006 on CDROM

[19] Eder, W.E. (2008) 'Aspects of Analysis and Synthesis in Design Engineering’, in Proc. CDEN 08, Halifax, N.S., 27-29 July 2008, on CD-ROM

[20] Eder, W.E. (2010a) 'Requirements to Properties - Iterative Problem Solving', in Proc. Canadian Engineering Education Association 2010 Inaugural Conference, 7-9 June 2010, Queen's University, Kingston, ON

[21] Hirtz, J, Stone, R.B., McAdams, D.A., Szykman, S. and Wood, K.L. (2002) 'A Functional Basis for Engineering Design: Reconciling and Evolving Previous Efforts', NIST Technical Note 1447, U.S. National Institute of Standards and Technology, 40 pages

[22] Maier, J.R.A. and Fadel, G.M. (2009) 'Affordance Based Design: A Rational Theory for Design', Research in Engineering Design, Vol. 20, No. 1, p. 13-27

[23] Maier, J.R., Troy, T., Johnson, P.J., Bobba, V. and Summers, J.D. (2010) 'Case Study Research Using Senior Design Projects: An Example Application', ASME-Journal of Mechanical Design, Paper 111011, Vol.132, No. 11, 8 pages

[24] Hubka, V. (1976) Theorie der Konstruktionsprozesse (Theory of Design Processes), Berlin: Springer-Verlag

[25] Hubka, V. and Eder, W.E. (1992) Engineering Design, Zürich: Heurista, $\left(2^{\text {nd }}\right.$ edition of Hubka, V., Principles of Engineering Design, London: Butterworth Scientific, 1982, translated and edited by W.E. Eder from Hubka, V., WDK 1 Allgemeines Vorgehensmodell des Konstruierens (General Procedural Model of Designing), Zürich, Heurista, 1980; translated into several other languages: French, M. Wyss (1980) Zürich: Heurista; Italian, U. Pighini (1982) Marsilo ed.; Czech, S. Hosnedl (1995) Zürich: Heurista, and others)

[26] Eder, W.E. (2012c) 'Engineering Design vs. Artistic Design - A Discussion', paper number 7 in Proc. Canadian
Engineering Education Association CEEA 2012 Conference, 17-20 June 2012, University of Manitoba, Winnipeg, MB

[27] Hubka, V., Andreasen, M.M. and Eder, W.E. (1988) Practical Studies in Systematic Design, London: Butterworths, (English edition of WDK 4 - Fallbeispiele, Zürich: Heurista, 1981 and 1983)

[28] Eder, W.E. (2009b) 'Case Study in Systematic Design Engineering - Smoke Gas Dust Precipitation', paper ASME DETC2009-86069 in Proceedings of the $6^{\text {th }}$ Symposium on International Design and Design Education, DEC 6, August 30 - September 2, San Diego, California, USA

[29] Eder, W.E. (2010b) 'Case Study in Systematic Design Engineering - Trapeze Demonstration Rig', paper ASME DETC2010-28065 in Proc. $7^{\text {th }}$ Symposium on International Design and Design Education, DEC 7, 15-18 August, Montreal, Quebec, Canada

[30] Eder, W.E. and Heffernan, P.J. (2009) 'A Case Study in Systematic and Methodical Design Engineering', in Proc. CDEN/C2C2 Conference 2009, 27-29 July, McMaster University, Hamilton, ON

[31] Hosnedl, S., Srp, Z., and Dvorak, J. (2008) 'Cooperation of Engineering and Industrial Designers on Industrial Projects', in Proc. 10th International Design Conference - DESIGN 2008, D. Marjanovic (Ed.), FMENA, Zagreb, p. 1227-1234

[32] Eder, W.E. (2012a) 'Case Example in Systematic Design Engineering - Leeboard Mounting', in Proc. International Design Conference - DESIGN 2012, Dubrovnik - Croatia, May 21-24, 2012

[33] Eder, W.E. (2012b) 'Case Example in Systematic Design Engineering - Propeller Shaft Bearing Arrangement', for Proc. International Design Conference - DESIGN 2012, Dubrovnik - Croatia, May 21-24, 2012

[34] Caravan Stage Barge (2010) http://www.caravanstage.org

[35] Eder, W.E., (2012d) 'Case Study in Systematic Design Engineering - Bow Thruster Covers', paper number 8 in Proc. Canadian Engineering Education Association CEEA 2012 Conference, 17-20 June 2012, University of Manitoba, Winnipeg, MB

[36] Eder, W.E. (2012e) 'Case Study in Systematic Design Engineering - Wind Tunnel Balance Model Support', paper number 9 in Proc. Canadian Engineering Education Association CEEA 2012 Conference, 17-20 June 2012, University of Manitoba, Winnipeg, MB

[37] Eder, W.E. (2009a) 'Why Systematic Design Engineering?' in Proc. $6^{\text {th }}$ Symposium on International Design and Design Education, August 30 - September 2, 2009, San Diego, California, USA, New York: ASME, paper number DETC2009-86067 